\title{
Isothermal titration calorimetry investigation of the interactions between vitamin B6-derived hydrazones and bovine and human serum albumin
}

\author{
Rossella Migliore ${ }^{1}$ Maksim N. Zavalishin ${ }^{2} \cdot$ George A. Gamov² $\cdot$ Tatiana R. Usacheva $^{2}$ - Valentin A. Sharnin ${ }^{2}$. \\ Giuseppa I. Grasso ${ }^{1} \cdot$ Carmelo Sgarlata ${ }^{1}[0$
}

Received: 3 June 2021 / Accepted: 3 January 2022 / Published online: 24 January 2022

(c) The Author(s) 2022

\begin{abstract}
The binding of low molecular weight compounds with the transport proteins of blood is an essential step of their delivery into living cells and thus the accurate investigation of the interactions occurring in solution at physiological conditions is crucial for the development of efficient biologically active molecules. In this work, we report on the complex species, stability constants and thermodynamic parameters for the binding reactions of hydrazones derived from pyridoxal-5'-phosphate (PLP) with bovine and human serum albumin (BSA and HSA) in neutral aqueous solution. The study has been carried out using isothermal titration calorimetry which allowed to directly obtain both binding constant and enthalpy change values for the systems investigated. The thermodynamic characterization in solution revealed that the PLP-hydrazone derivatives are able to effectively interact with both bovine and human serum albumin and enabled the determination of the driving forces for the molecular recognition process. The formation of the 1:1 complex was found to be always enthalpy favored and driven due to the insertion of the hydrazone moieties into the hydrophobic pockets of BSA or HSA.
\end{abstract}

Keywords Hydrazones $\cdot$ Vitamin $\mathrm{B}_{6} \cdot$ Serum albumins $\cdot$ ITC $\cdot$ Driving forces

\section{Introduction}

Hydrazones have a wide spectrum of biological and pharmacological properties; among others, antimicrobial, anticonvulsant, analgesic, anti-inflammatory, antitubercular, and antitumoral activities have been reported [1,2]. Studies on the binding features of hydrazones to plasma proteins such as human serum albumin (HSA) and bovine serum albumin (BSA) are important in biological, biomedical and pharmaceutical sciences since the strong binding can reduce the bioavailability and increase the half-life in vivo [3].

Maksim N. Zavalishin

zavalishin00@gmail.com

$\triangle$ Carmelo Sgarlata

sgarlata@unict.it

1 Dipartimento di Scienze Chimiche, Università degli Studi di Catania, Viale Andrea Doria 6, 95125 Catania, Italy

2 Ivanovo State University of Chemistry and Technology, Sheremetevsky av. 7, Ivavovo, Russian Federation 153000
The introduction of biological aldehydes into the hydrazone molecules can provide them with additional valuable properties. For example, pyridoxal-5'-phosphate (PLP), the active form of vitamin $\mathrm{B}_{6}$, is an aldehyde which can form Schiff bases and hydrazones. Pyridoxal-5'-phosphate is a cofactor for more than 140 enzymes (4\% of classified activities) [4] and PLP-dependent enzymes catalyze a wide range of reactions involving amino acids and amines, including transamination and $\alpha$-decarboxylation [5]. Hydrazone-derivatives of vitamin $\mathrm{B}_{6}$ drew attention due to their biological potential, particularly, antiproliferative [6] and antioxidant [7] activities. The ability of such compounds to form strong chelates with most cations can find applications to treat heavy metal poisoning and Wilson's disease $[8,9]$. Hydrazones derived from pyridoxal can also interfere with heme biosynthesis due to their iron-chelating properties [10] and cause damage to hematopoietic cells [11]. Thus, an examination of the binding properties of hydrazones derived from vitamin $B_{6}$ to transport proteins is of great relevance in view of both their beneficial and adverse effects.

There are a few papers describing the interaction of hydrazones of vitamin $\mathrm{B}_{6}$ with albumins in aqueous solution. The 
stability constants of pyridoxal isonicotinoyl hydrazone and its analogues as well as their $\mathrm{Fe}(\mathrm{III})$ complexes with BSA in aqueous solution were determined by spectrophotometric measurements. The complexes of BSA with Fe(III) form more stable adducts compared to the free hydrazones while the position of the halogen atom in the benzene ring of the hydrazide residue was found to have a negligible effect on the interaction with BSA [12]. The interaction of pyridoxal isonicotinoyl hydrazone with HSA was studied by circular dichroism, fluorescence titrations, and molecular docking. The circular dichroism technique showed that the addition of the hydrazone to the protein causes an insignificant change in its secondary structure [13]. The binding constants for a number of pyridoxal-5-phosphate-derived hydrazones with BSA were determined using spectrofluorimetric experiments [14]; however, the thermodynamic parameters and the binding forces for the interaction of these hydrazones obtained from vitamin $B_{6}$ with albumins in solution are still lacking.

An essential condition to obtain an in-depth understanding of the molecular basis of protein-ligand interactions is a thorough quantitative characterization of the energetics driving the complex formation. Isothermal titration calorimetry (ITC) is the only technique that allows studying directly the basic forces that characterize the binding of a small molecule to a macromolecule in solution as well as the nature of the interactions that stabilize the resulting complex by measuring the heat involved in the binding reaction $[15,16]$. The elucidation of the thermodynamic aspects of the binding is fundamental for both understanding the protein structure function and designing and developing more effective biological active molecules.

In this work, we report on the binding features of hydrazones derived from pyridoxal 5'-phosphate (Fig. 1) with bovine and human serum albumin in water at physiological pH by ITC experiments to gain insights into the energetics of the complexation processes. The determination of the entropic and enthalpic contribution to the standard Gibbs energy allowed for a detailed examination of the forces driving the molecular recognition events in solution $[17,18]$ and their dependence on both the ligand and protein properties and structure. The three hydrazones investigated were selected basing on the results of a preliminary computerbased screening conducted using Way2Drugs Predictive Services [19-22]. According to the modeling results, hydrazone derivatives can be effective inhibitors of $\beta$-adrenergic receptor kinase ( $\beta$ ARK) and can work as antitumor agents against the bladder carcinoma cell line (see Table S1). Inhibition of $\beta$ ARK is a promising way to combat heart failure [23] and thus the study of the binding interactions of these hydrazones with biological systems, such as serum albumins, is of great interest.

\section{Materials and methods}

\section{Materials}

Hydrazones derived from pyridoxal-5-phosphate and pyrazine-2-carboxylic, 4-pyridinecarboxylic, hydrazide 2-furoic acids, namely pyridoxal-5'-phosphate pyrazine-2-carbohydrazone (PLP-PRZ), pyridoxal-5'-phosphate isonicotinoylhydrazone (PLP-INH) and pyridoxal-5'-phosphate 2-furoylcarbohydrazone (PLP-2FH), were synthesized as previously reported [24]. Their purity was controlled through ${ }^{1} \mathrm{H}$ NMR spectroscopy. Bovine serum albumin and human serum albumin were purchased from Sigma-Aldrich (purity: 98\% and $99 \%$, respectively) and were used without further purification. Buffer solutions were prepared using the proper phosphate salt (Sigma-Aldrich) and their $\mathrm{pH}$ value was controlled potentiometrically. High purity water (Millipore, Milli-Q Element A 10 ultrapure water) and A grade glassware were employed throughout.

\section{ITC experiments}

ITC experiments were carried out at $25{ }^{\circ} \mathrm{C}$ with a nanoisothermal titration calorimeter Nano-ITC (TA Instruments) having an active cell volume of $0.988 \mathrm{~mL}$ and equipped with a $250 \mu \mathrm{L}$ injection syringe. The reaction mixture in the sample cell was stirred at $250 \mathrm{rpm}$ during the titration. (a)

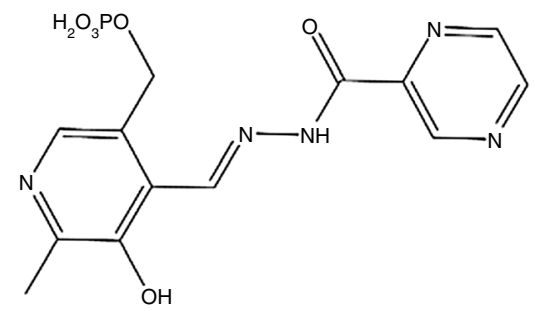

(b)

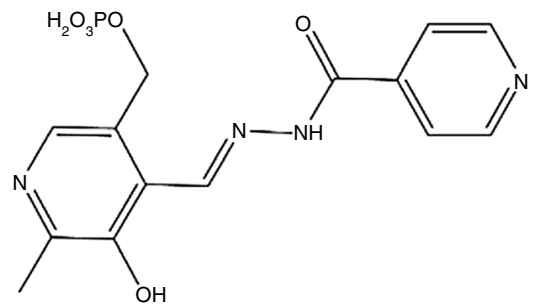

(c)

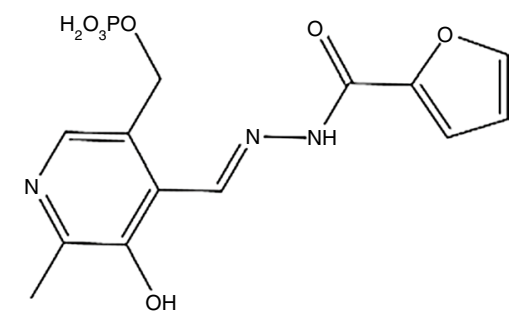

Fig. 1 Hydrazones derived from pyridoxal-5'-phosphate: a Pyridoxal-5'-phosphate pyrazine-2-carbohydrazone (PLP-PRZ); b Pyridoxal-5'phosphate isonicotinoylhydrazone (PLP-INH); c Pyridoxal-5'-phosphate 2-furoylcarbohydrazone (PLP-2FH) 
Measurements were run in the overfilled mode, which does not require any correction for liquid evaporation and for the presence of the vapor phase $[25,26]$. The power curve was integrated by using the NanoAnalyze software (TA Instruments) to obtain the gross heat evolved/absorbed in the reaction. The calorimeter was calibrated chemically by a test $\mathrm{HCl} / \mathrm{TRIS}$ reaction (Fig. S1) using the procedure previously described [27]. The instrument was also checked through an electrical calibration.

ITC measurements for the study of the ligand-protein complex formation were carried out by titrating a solution of the proper hydrazone derivative (4-6 mM) into a BSA or HSA solution $(0.15-0.25 \mathrm{mM})$. Both serum albumins and hydrazones were dissolved in phosphate buffer ( $\mathrm{pH}$ 7.4) with $I=0.250 \mathrm{M}$. The ionic strength was set close to the value of the intracellular ionic strength of the red blood cells [28]. The concentration of BSA and HSA stock solutions (stored in the dark at $4{ }^{\circ} \mathrm{C}$ ) was checked by UV-Vis spectroscopy prior to each calorimetric experiment [29]. Typically, three independent titrations were run for each hydrazone/serum albumin system in order to collect a proper number of points to obtain a satisfactory fit of the curve. The heats of dilution were determined in separate blank experiments by titrating solutions of each hydrazone (prepared in phosphate buffer) into a solution containing phosphate buffer only (Figs. S7-S9). The blank titrations were then optimized to obtain the "best blank". The "best blank" incremental heat corresponding to a given addition can easily be obtained from a plot of the type shown in Fig. S10 and can be subtracted from the raw incremental heat of reaction obtained at a specific addition to finally obtain the net reaction heat. Such a procedure, while being time consuming, reduces the effect of the "blank error" in the net heat. The net heats of reaction were analyzed by HypCal, a program which uses algorithms based on the well-tested routines that are utilized in the extensively cited programs Hyper*, modified and adapted for the specific characteristics of calorimetric data [30]. This software is designed for the determination of equilibrium constants and formation enthalpies of complexes in solution and deals with chemical models in which stoichiometry is specified explicitly rather than with binding models. The program can handle calorimetric data from more than one titration curve thus reducing the risk of artifacts.

The parameters are obtained by optimizing the agreement between observed and calculated reaction heats. The optimization is performed by means of a nonlinear least squares process, minimizing the function $(U)$ defined as

$U=\sum\left(Q_{\text {obs. }}-Q_{\text {calc. }}\right)^{2}$

where $Q_{\text {obs. }}$ is the observed heat for a given reaction step, corrected for the dilution (blank) effects, while $Q_{\text {calc. }}$ is the calculated heat change for a single reaction step and it is obtained as

$Q_{\text {calc. }}=-\sum \delta n \Delta H^{0}$

where $\delta n$ is the change in the number of moles of a reaction product and $\Delta H^{0}$ is the molar formation enthalpy of the reaction product. The sum is carried out over all the reaction steps of the specific chemical system. The squared residuals $\left(Q_{\text {obs. }}-Q_{\text {calc. }}\right)^{2}$ are summed over all the titration points. $\log K$ values and thermodynamic parameters were obtained, for each hydrazone-albumin system, by analyzing simultaneously the calorimetric data (net heat values vs. volume of titrant added) obtained from different independent titrations. An example of HypCal refinement output is illustrated in Fig. S11.

\section{Results and discussion}

A calorimetric study of the binding features of different hydrazones functionalized with pyridoxal 5 '-phosphate in the presence of either HSA or BSA was carried out in neutral aqueous solution to understand the influence of the structure of the hydrazone derivatives on the interactions with serum albumins. A typical ITC run of pyridoxal-5'-phosphate isonicotinoylhydrazone into HSA at $25^{\circ} \mathrm{C}(\mathrm{pH} 7.4$, phosphate buffer) is shown in Fig. 2. The calorimetric curves for all the hydrazone/HSA or BSA systems and the corresponding binding curves (net heat values) are shown in Figs. S2-S6.

For each hydrazone-protein system, multiple ITC runs were carried out and calorimetric data were analyzed simultaneously by HypCal [30], a software which enables to determine the species formed in solution, their stability constants and the values of $\Delta H$ and $\Delta S$ of formation. The binding constants and the thermodynamic parameters for the systems investigated are shown in Table 1 and Figs. 3 and 4.

The binding process between small molecules and proteins in solution may involve different interactions strictly related to their structural properties. Van der Waals forces, electrostatic and hydrophobic interactions are usually the main driving forces that occur in the recognition process [31-34]. Due to the specific structures of both hydrazones and serum albumins examined in this work, the binding events may be mainly attributed to (i) hydrophobic interactions between the aromatic moiety of the hydrazones and the hydrophobic cavity of the protein, (ii) electrostatic interactions between the phosphate group of the hydrazones and the polar amino groups of BSA/HSA, (iii) hydrogen bonding between the hydroxyl and phosphate groups of the hydrazones and the amino and hydroxyl groups of BSA/HSA and (iv) desolvation and/or structural re-arrangement of both the hydrazone and the protein upon complexation [35-37]. 

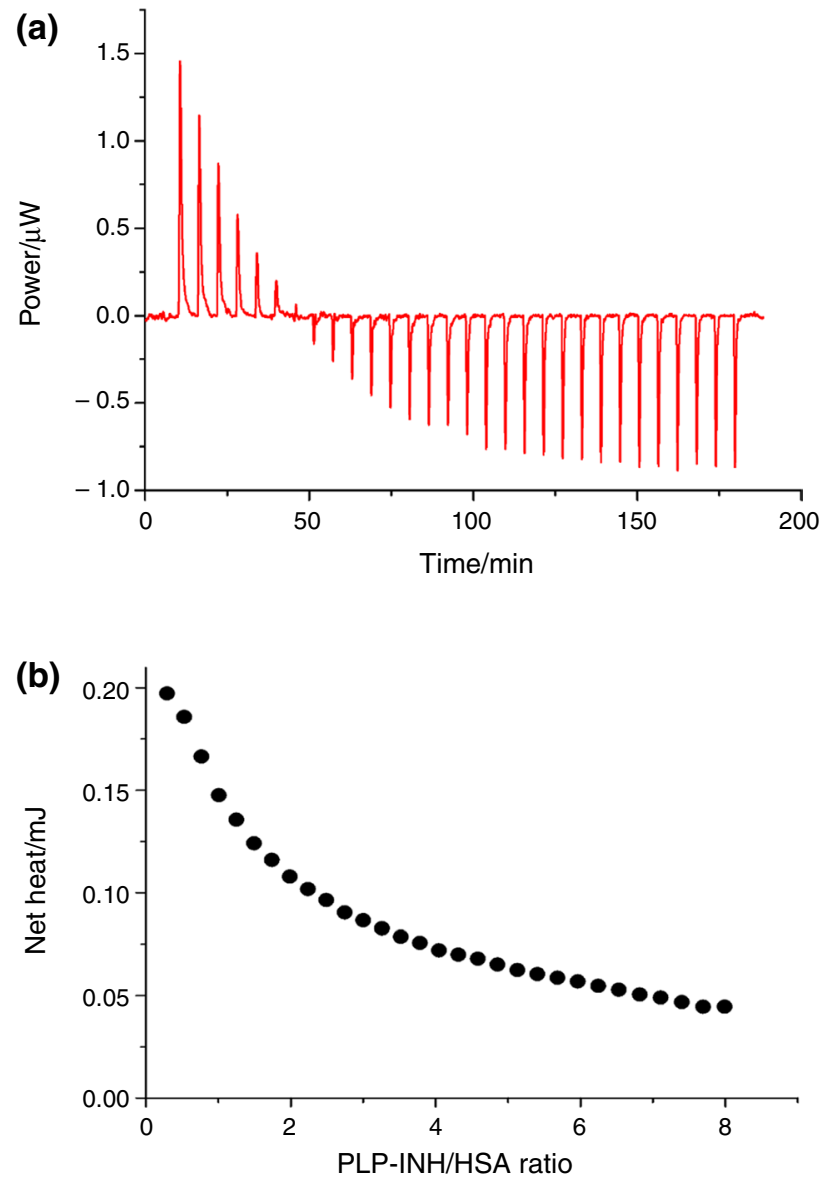

Fig. 2 a ITC curve of pyridoxal-5'-phosphate isonicotinoylhydrazone (PLP-INH) $5.7 \mathrm{mM}$ into human serum albumin $0.25 \mathrm{mM}$ at $25{ }^{\circ} \mathrm{C}$ in neutral aqueous solution (phosphate buffer, $\mathrm{pH}$ 7.4); $\mathbf{b}$ Integrated heat data

Since in any spontaneous binding process the Gibbs free energy change is negative, it is more appealing to discuss the solution thermodynamics of the binding events in terms of enthalpic and entropic contributions, which may be favored or unfavored and are more sensitive to ligand and/or protein structural changes, thus combining and accounting for multiple contributions to the complex formation. In any binding process, enthalpy changes reveal the formation or disruption of non-covalent interactions between the interacting

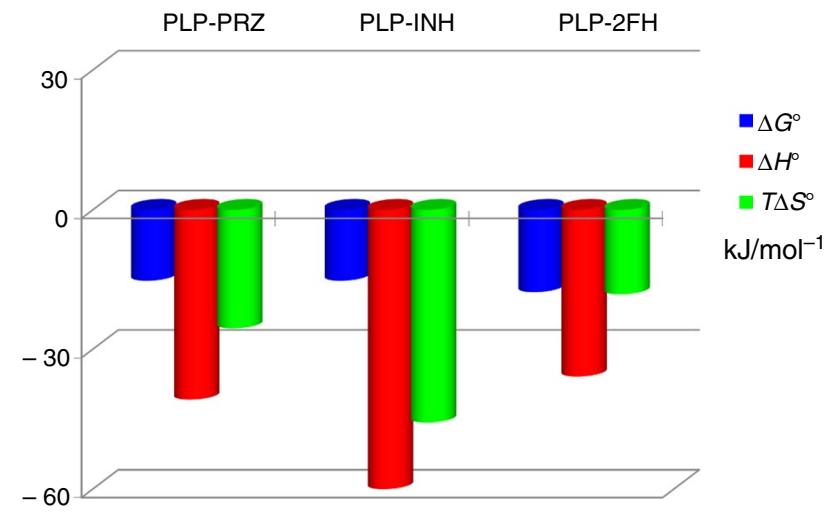

Fig. 3 Thermodynamic parameters for the complex formation of BSA with PLP-derived hydrazones at $25{ }^{\circ} \mathrm{C}$ in neutral aqueous solution (pH 7.4, phosphate buffer)

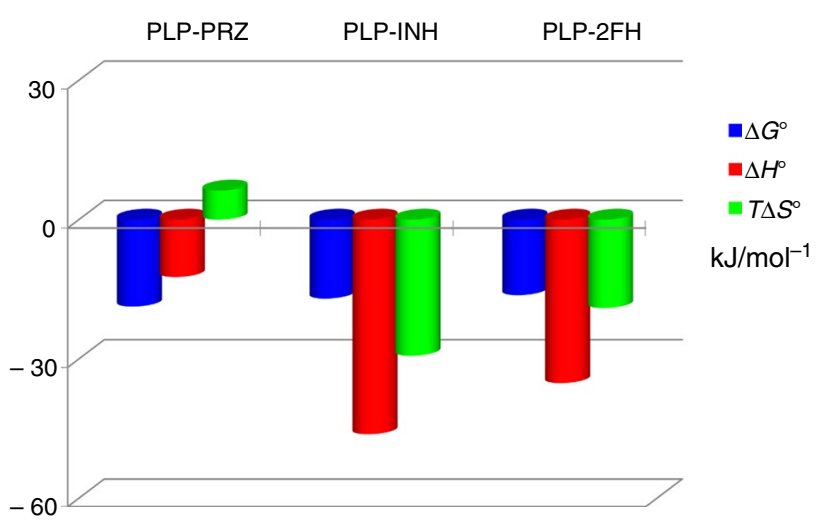

Fig. 4 Thermodynamic parameters for the complex formation of HSA with PLP-derived hydrazones at $25{ }^{\circ} \mathrm{C}$ in neutral aqueous solution ( $\mathrm{pH} 7.4$, phosphate buffer)

molecules as well as between them and the solvent while conformational and/or structural rearrangements and desolvation contribute to the entropy changes [38-41].

All PLP-derived hydrazones are able to form 1:1 complexes with both BSA and HSA in neutral aqueous solution. Other stoichiometries and their combinations were tested but were always rejected by the software.
Table $1 \log K$ values and thermodynamic parameters for the complex formation of BSA and HSA with PLPderived hydrazones at $25^{\circ} \mathrm{C}$ in neutral aqueous solution ( $\mathrm{pH} 7.4$, phosphate buffer) and $\mathrm{I}=0.25 \mathrm{M}$

\begin{tabular}{lllllc}
\hline & Hydrazone derivative & $\log K$ & $\Delta G^{0} / \mathrm{kJ} \mathrm{mol}^{-1}$ & $\Delta H^{0} / \mathrm{kJ} \mathrm{mol}^{-1}$ & $\Delta S^{0} / \mathrm{J} \mathrm{mol}^{-1} \mathrm{~K}^{-1}$ \\
\hline BSA & PLP-PRZ & $2.67(6)^{\mathrm{a}}$ & $-15.24(7)$ & $-40.73(4)$ & $-85(3)$ \\
& PLP-INH & $2.67(5)$ & $-15.24(3)$ & $-60.91(2)$ & $-154(1)$ \\
& PLP-2FH & $3.1(1)$ & $-17.70(5)$ & $-35.86(2)$ & $-61(2)$ \\
HSA & PLP-PRZ & $3.27(5)$ & $-18.7(1)$ & $-12.39(3)$ & $21(2)$ \\
& PLP-INH & $2.97(4)$ & $-16.95(3)$ & $-46.25(2)$ & $-98(1)$ \\
& PLP-2FH & $2.84(5)$ & $-16.21(6)$ & $-35.20(3)$ & $-64(2)$ \\
\hline
\end{tabular}

${ }^{a}$ Errors on the last significant figure are given in parentheses 
The stability of the complexes with BSA increases from PLP-PRZ and PLP-INH to PLP-2FH as previously observed by spectrofluorimetric experiments [14]. An opposite trend was found for the HSA-hydrazone systems and this evidence could be ascribed to the diverse interactions of the ligands with slightly different domains of the two serum proteins [42].

Differences found in the binding affinity values (but not in the trend) determined by fluorescence and ITC experiments for the BSA/hydrazone adducts may be attributed to the different features and observables of the techniques employed (which are sensitive to different aspects of the binding equilibria occurring in solution) as well as to the position assignment of the quencher and the fluorophore. Indeed, ITC measures the overall heat released/adsorbed by whatever reaction occurring in the calorimetric vessel (thus providing both stability constant and overall enthalpy change values) whereas the fluorescence measurements are based on the local environment changes around the tryptophan residues which occur upon guest binding. Thus, the cause of this deviation may be attributed to the limitation of fluorescence measurements (based on tryptophan emission) that may not give information about the protein regions which were far away from tryptophan residue [43]. The deviation between the binding constant values determined by fluorescence titrations and ITC experiments was reported earlier and the reasons for such mismatch were critically discussed [44].

The secondary structure of albumin is altered during the reaction with the hydrazones, as it was determined using IR-spectroscopy [14], and other small molecules, as indicated by a mismatch of the van't Hoff enthalpy value with that measured experimentally by ITC [45]. The change in the secondary structure of the protein has its own change in enthalpy [46-48], which results in additional heat evolving or absorbing during each injection of the titrant. These heat effects are dependent on the degree of change in the secondary structure of the protein and, therefore, the net heats of reaction may contain inaccuracies or supplementary contributions from side processes which is hard to take into account. For this reason, the $\log K$ values obtained from fluorimetry [14] and ITC experiments may show some differences. The dependence of both binding constant and change in enthalpy on the concentration of background electrolytes or dissolved organic compounds is a known phenomenon; for example, some authors reported the changes in $\alpha$-helices content in lysozyme upon addition of $\mathrm{NaCl}$ and the corresponding decrease in $\log K$ and increase in $\Delta H_{\mathrm{r}}$ [49]. $\mathrm{NaCl}$ was also shown to weaken the binding between drug and HSA [50]. Another potential source of inaccuracy/discrepancy is the hardly accountable change in the degree of hydration of proteins and small molecules $[50,51]$. Errors may also arise from neglecting the side processes involving buffers, e.g., protolytic equilibria. However, in our experiments ignoring these reactions was justified as phosphate salts used in buffer have a small value for the enthalpy of ionization [45]. Finally, the changes in the conformation of hydrazones [52] may also contribute to the overall enthalpy of small molecule-protein binding processes.

The thermodynamic parameters indicate that the interactions of the three PLP-derived hydrazones with BSA and HSA are slightly different. The splitting of the free energy values into the $\Delta S$ and $\Delta H$ components allows for the determination of the driving forces of the molecular recognition equilibria. In all cases, the binding processes are enthalpy favored and driven: the interactions involving the insertion of the aromatic rings of the hydrazone derivatives into the hydrophobic pockets of BSA or HSA always result in an exothermic process. Negative $\Delta H$ values are mainly due to electrostatic interactions, hydrogen bonding and van der Waals forces between the ligand functional groups and the amino acid residues on the serum albumins.

On the other hand, all processes, except the reaction of PLP-PRZ with HSA, are entropy unfavoured due to the loss of degrees of freedom of the system resulting from the complex formation. The interaction of PLP-PRZ and HSA is entropically favored likely due to a significant desolvation contribution. The complexes with increased stability (e.g., the complexes of PLP-PRZ and PLP-INH with HSA, if compared with BSA) are those having smaller entropic loss/cost (or having a gain, as in the case of PLP-PRZ/HSA) and this may be ascribable to some conformational or structural re-arrangement and a major desolvation process which favorably contribute to the Gibbs free energy value [53, 54].

The enthalpy-entropy compensation is widely recalled in thermodynamic analyses of proteins, ligands and nucleic acids.

In principle, a linear correlation between $\Delta S$ and $\Delta H$ in the binding process for a series of homologous compounds is considered as strong evidence of $H-S$ compensation. The linear correlation occurring for the binding of PLPderived hydrazones with both BSA and HSA clearly indicates enthalpy-entropy compensation, that is, a change in enthalpy is compensated by a corresponding change in the entropic term, as reported for similar systems $[55,56]$.

Despite this phenomenon has been a subject of debate for many years, there are two considerations supporting the enthalpy-entropy compensation effect for the adducts investigated here. Firstly, the technique employed (ITC) minimizes the inherent limitations displayed by entropy and enthalpy data obtained through a van't Hoff analysis, that makes the two variables statistically correlated. In addition, the slope of the plots shown in Fig. 5 is 0.93 for BSA (blue line) and 0.94 for HSA (green line), which are close to unity as expected and described for analogous systems [57-59]. 


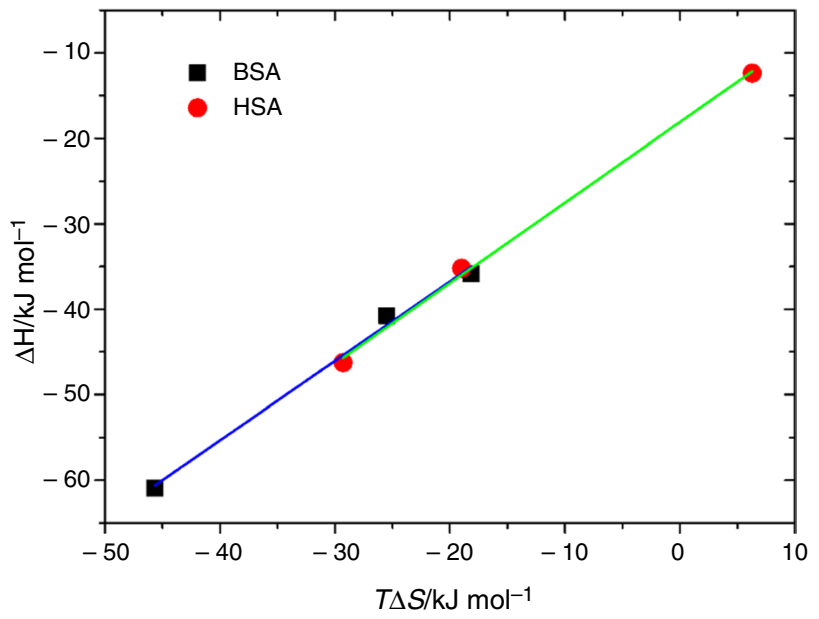

Fig. 5 Enthalpy-entropy compensation of PLP-derived hydrazones with BSA (blue line) and HSA (green line) in neutral aqueous solution ( $\mathrm{pH} 7.4$, phosphate buffer) at $25^{\circ} \mathrm{C}$. (Color figure online)

\section{Conclusions}

The ligand-protein binding of pyridoxal-5-phosphate-based hydrazones with both bovine and human serum albumin was examined by ITC measurements in neutral aqueous solution. Calorimetric data allowed to unveil the often opposing entropic and enthalpic contributions to the overall binding process. The molecular recognition events leading to the formation of the 1:1 complex are enthalpically favored and driven resulting from the attractive interactions involved in the insertion of the hydrazone derivatives into the hydrophobic pockets of BSA and HSA. The complex formation causes a loss of degrees of freedom of the adducts resulting in an unfavoured entropic contribution. Nevertheless, an entropy gain, likely due to conformational and/or structural re-arrangements along with a desolvation contribution, was found for the PLP-PRZ/HSA system. All complexes exhibit comparable free energy contents resulting from a negative entropy contribution that compensates for the favorable enthalpy term.

These results provide important insights for the design and development of efficient biologically active molecules in solution and can be conveniently used to assess the bioavailability of hydrazones in the organisms.

Supplementary Information The online version contains supplementary material available at https://doi.org/10.1007/s10973-022-11200-2.

Authors' contributions Conceptualization: Valentin A. Sharnin and Carmelo Sgarlata; Methodology: Rossella Migliore, Maksim N. Zavalishin, and Giuseppa I. Grasso; Formal analysis and investigation: Rossella Migliore, Maksim N. Zavalishin, and Giuseppa I. Grasso; Writing-original draft preparation: Rossella Migliore, Maksim N. Zavalishin, and George A. Gamov; Writing-review and editing:
Tatiana R. Usacheva, Carmelo Sgarlata, and George A. Gamov; Funding acquisition: Tatiana R. Usacheva, Carmelo Sgarlata, Maksim N. Zavalishin, and George A. Gamov; Resources: Carmelo Sgarlata, Maksim N. Zavalishin, and George A. Gamov; Supervision: Tatiana R. Usacheva, Valentin A. Sharnin, and Carmelo Sgarlata.

Funding This study was carried out with the financial support of the Council on grants of the President of the Russian Federation (project СП-1556.2021.4), the Ministry of Science and Higher Education of the Russian Federation (hydrazones synthesis and purification, compounds purity control,mathematical planning of experiments, data analysis, project FZZW-2020-0009) as well as of Italian MIUR (PRIN 2015 2015MP34H3) and University of Catania (Piano della Ricerca d'Ateneo 2016-18, linea 2 and PIACERI 2020-22, linea 2). MNZ was awarded a Grant for Foreign Citizen (2019-20) from Italian MAECI. Open access funding provided by University of Catania within the CRUI-CARE agreement.

\section{Declarations}

Conflict of interest The authors have no conflicts of interest to declare that are relevant to the content of this article.

Open Access This article is licensed under a Creative Commons Attribution 4.0 International License, which permits use, sharing, adaptation, distribution and reproduction in any medium or format, as long as you give appropriate credit to the original author(s) and the source, provide a link to the Creative Commons licence, and indicate if changes were made. The images or other third party material in this article are included in the article's Creative Commons licence, unless indicated otherwise in a credit line to the material. If material is not included in the article's Creative Commons licence and your intended use is not permitted by statutory regulation or exceeds the permitted use, you will need to obtain permission directly from the copyright holder. To view a copy of this licence, visit http://creativecommons.org/licenses/by/4.0/.

\section{References}

1. Rollas S, Güniz KS. Biological activities of hydrazone derivatives. Molecules. 2007;12(8):1910-39.

2. Nogueira CM, dos Santos CL, Lourenco MC, de Souza MVN. Design, synthesis and anti-tuberculosis activity of hydrazones and $\mathrm{N}$-acylhydrazones containing vitamin $\mathrm{B}_{6}$ and different heteroaromatic nucleus. Lett Drug Design Disc. 2019;16(7):792-8.

3. Kragh-Hansen U, Chuang VT, Otagiri M. Practical aspects of the ligand-binding and enzymatic properties of human serum albumin. Biol Pharm Bull. 2002;25(6):695-704.

4. Percudani R, Peracchi A. The $\mathrm{B}_{6}$ database: a tool for the description and classification of vitamin B6-dependent enzymatic activities and of the corresponding protein families. BMC Bioinform. 2009;273:1-8.

5. Eliot AC, Kirsch JF. Pyridoxal phosphate enzymes: mechanistic, structural, and evolutionary considerations. Ann Rev Biochem. 2004;73:383-415.

6. Richardson DR, Tran EH, Ponka P. The potential of iron chelators of the pyridoxal isonicotinoyl hydrazone class as effective antiproliferative agents. Blood. 1995;86(11):4295-306.

7. Hermes-Lima M, Gonçalves MS, Andrade RG Jr. Pyridoxal isonicotinoyl hydrazone (PIH) prevents copper-mediated in vitro free radical formation. Mol Cell Biochem. 2001;228(1-2):73-82.

8. Zavalishin MN, Gamov GA, Khokhlova AY, Gashnikova AV, Sharnin VA. Stability of $\mathrm{Co}(\mathrm{III}), \mathrm{Ni}(\mathrm{II})$, and $\mathrm{Cu}(\mathrm{II})$ complexes 
with 2-furan- and 2-thiophenecarboxyhydrazones of pyridoxal5 -phosphate in neutral aqueous solutions. Russ J Inorg Chem. 2020;65:119-25.

9. Richardson DR, Ponka P. Pyridoxal isonicotinoyl hydrazone and its analogs: potential orally effective iron-chelating agents for the treatment of iron overload disease. J Lab Clin Med. 1998;131(4):306-15.

10. Buss JL, Neuzil J, Gellert N, Weber C, Ponka P. Pyridoxal isonicotinoyl hydrazone analogs induce apoptosis in hematopoietic cells due to their iron-chelating properties. Biochem Pharmacol. 2003;65(2):161-72.

11. Edwards A, Lu Y, Low J, Wu J, Lee RE, Chen T. The isoniazid metabolites hydrazine and pyridoxal isonicotinoyl hydrazone modulate heme biosynthesis. Toxicol Sci. 2018;168(1):209-24.

12. Buss JL, Arduni E, Ponka P. Mobilization of intracellular iron by analogs of pyridoxal isonicotinoyl hydrazone (PIH) is determined by the membrane permeability of the iron-chelator complexes. Biochem Pharmacol. 2002;64(12):1689-701.

13. Merlot AM, Sahni S, Lane DJR, Fordham AM, Pantarat N, Hibbs DE, Richardson V, Doddareddy MR, Ong JA, Huang MLH, Richardson DR, Kalinowski DS. Potentiating the cellular targeting and anti-tumor activity of Dp44mT via binding to human serum albumin: two saturable mechanisms of Dp44mT uptake by cells. Oncotarget. 2015;6:10374-98.

14. Gamov GA, Meshkov AN, Zavalishin MN, Petrova MV, Khokhlova AY, Gashnikova AV, Sharnin VA. Binding of pyridoxal, pyridoxal 5'-phosphate and derived hydrazones to bovine serum albumin in aqueous solution. Spectrochim Acta A. 2020;233:118165.

15. Arena G, Sgarlata C. Modern calorimetry: an invaluable tool in supramolecular chemistry. In: Atwood JL, editor. Comprehensive supramolecular chemistry II, vol. 2. Oxford: Elsevier; 2017. p. 213-37.

16. Schmidtchen FP. Isothermal titration calorimetry in supramolecular chemistry. In: Steed JW, Gale PA, editors. Supramolecular chemistry: from molecules to nanomaterials, vol. 2. New York: Wiley; 2012. p. 275-96.

17. Migliore R, Granata G, Rivoli A, Consoli GML, Sgarlata C. Binding affinity and driving forces for the interaction of calixarenebased micellar aggregates with model antibiotics in neutral aqueous solution. Front Chem. 2021;8:626467.

18. Bonaccorso C, Migliore R, Volkova MA, Arena G, Sgarlata C. Self-assembling of supramolecular adducts by sulfonato-calix[4] arene and pyridinium gemini guests in neutral aqueous solution. Thermochim Acta. 2017;656:47-52.

19. http://www.way2drug.com/passonline/predict.php. (Accessed October 18, 2021).

20. Way2Drugs, Predictive Services: Cell Line Cytotoxicity Predictor. http://www.way2drug.com/Cell-line/index.php. Accessed 18 Oct 2021.

21. Lagunin AA, Dubovskaja VI, Rudik AV, Pogodin PV, Druzhilovskiy DS, Gloriozova TA, Filimonov DA, Sastry NG, Poroikov VV. CLC-Pred: a freely available web-service for in silico prediction of human cell line cytotoxicity for drug-like compounds. PLoS ONE. 2018;13(1):e0191838

22. Poroikov VV, Filimonov DA, Borodina YV, Lagunin AA, Kos A. Robustness of biological activity spectra predicting by computer program PASS for noncongeneric sets of chemical compounds. J Chem Inf Comput Sci. 2000;40(6):1349-55.

23. Petrofski JA, Koch WJ. The $\beta$-adrenergic receptor kinase in heart failure. J Mol Cell Cardiol. 2003;35(10):1167-74.

24. Gamov GA, Kiselev AN, Aleksandriiskii VV, Sharnin VA. Influence of regioisomerism on stability, formation kinetics and ascorbate oxidation preventive properties of Schiff bases derived from pyridinecarboxylic acids hydrazides and pyridoxal 5'-phosphate. J Mol Liq. 2017;242:1148-55.
25. Bundle DR, Sigurskjold BW. Determination of accurate thermodynamics of binding by titration microcalorimetry. Methods Enzymol. 1994;247:288-305.

26. Hansen LD, Fellingham GW, Russell DJ. Simultaneous determination of equilibrium constants and enthalpy changes by titration calorimetry: methods, instruments, and uncertainties. Anal Biochem. 2011;409(2):220-9.

27. Sgarlata C, Zito V, Arena G. Conditions for calibration of an isothermal titration calorimeter using chemical reactions. Anal Bioanal Chem. 2013;405(2-3):1085-94.

28. Mouat MA, Manchester KL. The intracellular ionic strength of red cells and the influence of complex formation. Comp Haematol Int. 1998;8(1):58-60.

29. Peters T. Advances in protein chemistry. New York: Academic Press; 1985.

30. Arena G, Gans P, Sgarlata C. HypCal, a general-purpose computer program for the determination of standard reaction enthalpy and binding constant values by means of calorimetry. Anal Bioanal Chem. 2016;408(23):6413-22.

31. Save SN, Choudhary S. Elucidation of energetics and mode of recognition of green tea polyphenols by human serum albumin. J Mol Liq. 2018;265:807-17.

32. Precupas A, Sandu R, Neculae AVF, Neacsu A, Popa VT. Calorimetric, spectroscopic and computational investigation of morin binding effect on bovine serum albumin stability. J Mol Liq. 2021;333:115953.

33. He T, Liang Q, Luo T, Wang Y, Luo G. Study on interactions of phenolic acid-like drug candidates with bovine serum albumin by capillary electrophoresis and fluorescence spectroscopy. J Solution Chem. 2010;39(11):1653-64.

34. Di Carluccio C, Forgione MC, Martini S, Berti F, Molinaro A, Marchetti R, Silipo A. Investigation of protein-ligand complexes by ligand-based NMR methods. Carbohydr Res. 2021;503:108313.

35. de Carvalho Bertozo L, Maszota-Zieleniak M, Bolean M, Ciancaglini P, Samsonov SA, Ximenes VF. Binding of fluorescent dansyl amino acids in albumin: when access to the protein cavity is more important than the strength of binding. Dyes Pigm. 2021;188:109195.

36. Escobar L, Ballester P. Molecular recognition in water using macrocyclic synthetic receptors. Chem Rev. 2021;121(4):2445-514.

37. Prozeller D, Morsbach S, Landfester K. Isothermal titration calorimetry as a complementary method for investigating nanoparticle-protein interactions. Nanoscale. 2019;11(41):19265-73.

38. Claveria-Gimeno R, Vega S, Abian O, Velazquez-Campoy A. A look at ligand binding thermodynamics in drug discovery. Expert Opin Drug Discov. 2017;12(4):363-77.

39. Giglio V, Sgarlata C, Vecchio G. Novel amino-cyclodextrin crosslinked oligomer as efficient carrier for anionic drugs: a spectroscopic and nanocalorimetric investigation. RSC Adv. 2015;5:16664-71.

40. Bonaccorso C, Brancatelli G, Forte G, Arena G, Geremia S, Sciotto D, Sgarlata C. Factors driving the self-assembly of watersoluble calix[4]arene and gemini guests: a combined solution, computational and solid-state study. RSC Adv. 2014;4:53575-87.

41. Sgarlata C, Mugridge JS, Pluth MD, Zito V, Arena G, Raymond $\mathrm{KN}$. Different and often opposing forces drive the encapsulation and multiple exterior binding of charged guests to a $\mathrm{M}_{4} \mathrm{~L}_{6}$ supramolecular vessel in water. Chem Eur J. 2017;23:16813-8.

42. Naveenraj S, Anandan S. Binding of serum albumins with bioactive substances-nanoparticles to drugs. J Photochem Photobiol C. 2013;14:53-71.

43. Ojha H, Mishra K, Hassan MI, Chaudhury NK. Spectroscopic and isothermal titration calorimetry studies of binding interaction 
of ferulic acid with bovine serum albumin. Thermochim Acta. 2012;548:56-64.

44. Bakar KA, Feroz SR. A critical view on the analysis of fluorescence quenching data for determining ligand-protein binding affinity. Spectrochim Acta A Mol Biomol Spec. 2019;223:117337.

45. Xi J, Fan L. Study on the binding of puerarin to bovine serum albumin by isothermal titration calorimetry and spectroscopic approaches. J Therm Anal Calorim. 2010;102:217-23.

46. Senske M, Törk L, Born B, Havenith M, Herrmann C, Ebbinghaus $\mathrm{S}$. Protein stabilization by macromolecular crowding through enthalpy rather than entropy. J Am Chem Soc. 2014;136(25):9036-41.

47. Poland D. Contribution of secondary structure to the heat capacity and enthalpy distribution of the unfolded state in proteins. Biopolymers. 2002;63(1):59-65.

48. Cliff MJ, Williams MA, Brooke-Smith J, Barford D, Ladbury JE. Molecular recognition via coupled folding and binding in a TPR domain. J Mol Biol. 2005;346(3):717-32.

49. Panja S, Halder M. Exploration of electrostatic interaction in the hydrophobic pocket of lysozyme: importance of ligand-induced perturbation of the secondary structure on the mode of binding of exogenous ligand and possible consequences. J Photochem Photobiol B. 2016;161:253-65.

50. Paul BK, Ghosh N, Mukherjee S. Interplay of multiple interaction forces: binding of norfloxacin to human serum albumin. J Phys Chem B. 2015;119(41):13093-102.

51. Sultan NA, Swamy MJ. Energetics of carbohydrate binding to Momordica charantia (bitter gourd) lectin: an isothermal titration calorimetric study. Arch Biochem Biophys. 2005;437(1):115-25.

52. Pogonin AE, Gamov GA, Zavalishin MN, Sharnin VA. Conformational behavior of hydrazone derived from pyridoxal 5'-phosphate and isoniazid. Izv Vyssh Uchebn Zaved, Ser Khim Khim Tekhn. 2018;61:101-7.
53. Migliore R, D’Antona N, Sgarlata C, Consoli GML. Co-loading of temozolomide and curcumin into a calix[4]arene-based nanocontainer for potential combined chemotherapy: binding features, enhanced drug solubility and stability in aqueous medium. Nanomaterials. 2021;11(11):2930.

54. Sgarlata C, Schneider BL, Zito V, Migliore R, Tegoni M, Pecoraro VL, Arena G. Lanthanide identity governs guest-induced dimerization in $\mathrm{Ln}^{\mathrm{III}}\left[15-\mathrm{MC}_{\mathrm{Cu}}\right.$ II $\left.\left.\mathrm{N}(\mathrm{L}-\mathrm{pheHA})^{-5}\right]\right)^{3+}$ metallacrowns. Chem Eur J. 2021. https://doi.org/10.1002/chem.202103263.

55. Wang Q, Chen WQ, Liu XY, Liu Y, Jiang FL. Thermodynamic implications and time evolution of the interactions of near-infrared $\mathrm{PbS}$ quantum dots with human serum albumin. ACS Omega. 2021;6(8):5569-81.

56. Bolel P, Datta S, Mahapatra N, Halder M. Spectroscopic investigation of the effect of salt on binding of tartrazine with two homologous serum albumins: quantification by use of the Debye-Hückel limiting law and observation of enthalpy-entropy compensation. J Phys Chem B. 2012;116(34):10195-204.

57. Olsson TS, Ladbury JE, Pitt WR, Williams MA. Extent of enthalpy-entropy compensation in protein-ligand interactions. Protein Sci. 2011;20(9):1607-18.

58. Sharp K. Entropy-enthalpy compensation: fact or artifact? Protein Sci. 2001;10(3):661-7.

59. Lelis CA, Nunes NM, de Paula HMC, Coelho YL, da Silva LHM, dos Santos Pires AC. Insights into protein-curcumin interactions: kinetics and thermodynamics of curcumin and lactoferrin binding. Food Hydrocoll. 2020;105:105825.

Publisher's Note Springer Nature remains neutral with regard to jurisdictional claims in published maps and institutional affiliations. 